\title{
Morphology as a key to behavioural flexibility: body shape and swimming variability in the dimorphic crucian carp
}

\author{
Lars B. Pettersson
}

Pettersson, L. B. 2007. Morphology as a key to behavioural flexibility: body shape and swimming variability in the dimorphic crucian carp. - Web Ecology 7: 113-119.

\begin{abstract}
Swimming trajectories of length-matched deep-bodied and shallow-bodied crucian carp were quantified in the laboratory using motion analysis software and compared in terms of swimming velocity, turning behaviour and associated coefficients of variation. The mean velocities of the two morphs were similar, but slower than predicted, and there was no difference in turning behaviour. In line with predictions from analysis of power curve steepness, swimming velocities of deep-bodied, high-drag individuals were significantly less variable than shallow-bodied conspecifics, thus indicating an association between body shape behavioural flexibility in terms of swimming variability.
\end{abstract}

Pettersson, L. B. (lars.pettersson@zooekol.lu.se), Dept of Ecology, Ecology Building, Lund Univ., SE-223 62 Lund, Sweden.

Swimming behaviour in fish is commonly analysed in terms of energy optimization at constant velocities (Blake 1983, Videler 1993, but see Tang et al. 2000). Considerably less is known about the use of variable velocities, despite unsteady swimming being the dominant swimming behaviour in many situations (Webb and Gardiner Fairchild 2001, Neumeister et al. 2004). A number of considerations can influence how a fish selects its swimming velocity and, indirectly, the degree to which the swimming velocity varies, e.g. habitat complexity (Eklöv and Persson 1995, Svanbäck and Eklöv 2004), predator avoidance (Krause et al. 1998, Pettersson et al. 2000), foraging behaviour (Grossman et al. 2002), migration (Castro-Santos 2005), and mate choice (Magellan et al. 2005). Interestingly, there is also reason to expect intraspecific variation in morphology to influence swimming variability. In a theoretical analysis, Pettersson and Hedenström (2000) demonstrated that the power curve, i.e. the relation between metabolic expenditure and locomotion, not only predicts the optimal velocities for sustained swimming (cf. Videler
1993), but also implicitly predicts behavioural flexibility in terms of swimming variability. Power curve steepness generally increases with increasing drag (Webb 1975) and using this relation, it was shown that fish with low-drag body shapes should be more likely to use a broad range of swimming velocities, whereas fish with high-drag body shapes should be substantially less variable in swimming velocity (Pettersson and Hedenström 2000). The cause of this effect is that high-drag individuals face small, but consistently higher costs of deviating from optimal swimming velocities (Pettersson and Hedenström 2000). Hence, in dimorphic or polymorphic species with significant power curve differences between morphs, this would indicate an association between ecological energetics, morphology, and behaviour. While intraspecific variation in body shape among fish is well documented (Endler 1995, Brönmark et al. 1999, Robinson and Parsons 2002, Snorrason and Skúlason 2004), sometimes demonstrating physiological differences between morphs (Pettersson and Brönmark 1999, Odell et al. 2003) the degree to which morphologi- 
cal differences correlate with effects on flexible swimming behaviour is largely unknown.

In the present study, swimming variability in relation to body morphology was tested using a dimorphic species, the crucian carp (Carassius carassius). In absence of predators, crucian carp form dense populations consisting of shallow-bodied individuals, whereas populations that coexist with predators are less numerous and consist of deepbodied individuals (Brönmark et al. 1999). The deeper body depth can be induced by chemical cues from piscivorous fish (Brönmark and Pettersson 1994) and constitutes a morphological defence against gape-limited predators (Brönmark et al. 1999). Because of its shape, the deepbodied morph suffers a significantly higher drag than the shallow-bodied morph, and the corresponding power curves are significantly steeper for a given body mass or length (Pettersson and Brönmark 1999). Following Pettersson and Hedenström (2000), deep-bodied individuals were hypothesized to be less variable in terms of swimming velocity than shallow-bodied conspecifics.

\section{Material and methods}

Experimental fish were collected in ponds nearby Lund, southern Sweden. Shallow-bodied crucian carp $(\mathrm{n}=16$, $91.9 \pm 2.8 \mathrm{~mm}$ total length, $11.9 \pm 0.8 \mathrm{~g}$, depth : length ratio $0.293 \pm 0.002$, mean $\pm S D$ ) were collected from a pond without piscivores, whereas deep-bodied individuals $(\mathrm{n}=12,92.7 \pm 3.5 \mathrm{~mm}, 17.0 \pm 1.5 \mathrm{~g}$, depth : length ratio $0.337 \pm 0.004)$ were collected from a pond with piscivores. Individuals of similar length from both populations were selected for the experiment $\left(t\right.$-test: $\left.t_{26}=0.66, p=0.52\right)$. The rationale for this choice was to standardise available forward thrust and the expected routine swimming velocity (Pettersson and Hedenström 2000, Webb and Gardiner Fairchild 2001). Although it should be noted that length matching individuals necessarily means that deep-bodied individuals had a greater body mass ( $\mathrm{t}$-test: $\mathrm{t}_{26}$ $=12.148, \mathrm{p}<0.0001$ ), while shallow-bodied fish were more fusiform (Wilcoxon two-sample test: $\mathrm{Z}=4.446, \mathrm{n}=$ $28, p<0.0001$ ), the design sought the best compromise between the need to standardise velocities while investigating effects of phenotypic variation. In the crucian carp system, both this experimental design and Ancova-based experimental designs have been used (cf. Pettersson and Brönmark 1999, Pettersson et al. 2000) and the results have been comparable. After capture, crucian carp were kept at $+14^{\circ} \mathrm{C}$ in $165 \mathrm{l}$ aquaria and acclimatised to indoor conditions for a minimum of 2 months. The light regime was 12:12 h light: dark and the fish were fed frozen chironomids and flake food daily.

The experimental set-up consisted of four circular tanks (Ø $59 \mathrm{~cm}$; Fig. 1). The tanks were located behind a blind and were illuminated by indirect light from Osram fluorescent tubes at $0.25 \pm 0.02 \mu \mathrm{E} \mathrm{m}^{-2}$. All four tanks had cen- trally placed airstones and were monitored from an overhead Sony DXC-107 AP video camera linked to a Panasonic NV-SD40 video recorder. Each trial started by adding one individual to each of the experimental tanks and allowing the fish to acclimate for $25 \mathrm{~min}$, a period sufficient to resume routine swimming speed in this species (Pettersson et al. 2000). Swimming trajectories were then quantified continuously for 5 min (sampling frequency 1 $\mathrm{Hz}$ ), using the motion analysis software Ethovision 1.90 (Noldus Inc. 1997). As characteristic measures of swimming behaviour, the mean velocity, coefficient of variation for velocity, absolute meander, and coefficient of variation for absolute meander were selected. Absolute meander estimates turning rate and represents the unsigned change in direction of movement of an object relative to the distance moved by the object (Noldus Inc. 1997). Mean velocity, absolute meander, and their corresponding coefficients of variation were averaged over the full $5 \mathrm{~min}$ period. Additionally, to illustrate variability in terms of swimming velocity, cumulative frequency distributions were generated for both morphs using per minute averages ( 5 consecutive per individual). Data from Pettersson (1999) and Pettersson and Brönmark (1999) were used to estimate power curves and swimming velocities associated with minimum energy cost per unit distance, $\mathrm{U}_{\mathrm{mc}}$ (Tucker 1975, Videler 1993). Cost of transport, a dimensionless performance measure, (COT, Tucker 1975, Pettersson and Hedenström 2000) for both morphs were calculated at their corresponding $\mathrm{U}_{\mathrm{mc}}$. The power curves used (Pettersson 1999, Pettersson and Brönmark 1999) were adjusted to the experimental temperature (i.e. from $+16^{\circ} \mathrm{C}$ to $+14^{\circ} \mathrm{C}$ ) using estimates of temperature dependence in closely related cyprinids (Kaufmann and Wieser 1992, Hölker 2003). Statistical tests followed Zar (1999) and Siegel and Castellan (1988), and model assumptions were tested using graphical methods according to standard practise (Zar 1999). All statistical tests we carried out using SAS 8.2 (SAS Inst. 1999).

\section{Results}

Mean swimming velocity did not differ between morphs (Fig. 2a, shallow-bodied fish: $4.5 \pm 1.8 \mathrm{~cm} \mathrm{~s}^{-1}$; deep-bodied $4.4 \pm 1.4 \mathrm{~cm} \mathrm{~s}^{-1}$; t-test: $\mathrm{t}_{26}=0.079, \mathrm{p}=0.94$ ), but the coefficient of variation for swimming velocity was significantly lower in deep-bodied fish (Fig. 2b, shallow-bodied fish: $0.70 \pm 0.09$; deep-bodied $0.62 \pm 0.05$, $\mathrm{t}$-test: $\mathrm{t}_{26}=$ 2.606, $\mathrm{p}=0.015$ ). When analysed in detail, cumulative frequency distributions for the two morphs' swimming velocities indicated that deep-bodied individuals used a more restricted range of velocities than shallow-bodied individuals (Fig. 3). The mean turning rate did not differ between morphs (absolute meander for shallow-bodied fish: $23.8 \pm 8.7$ degrees $\mathrm{cm}^{-1}$, deep-bodied fish: $18.9 \pm 4.4$ degrees $\mathrm{cm}^{-1}$; Wilcoxon two-sample test: $\mathrm{Z}=1.439, \mathrm{n}=$ 

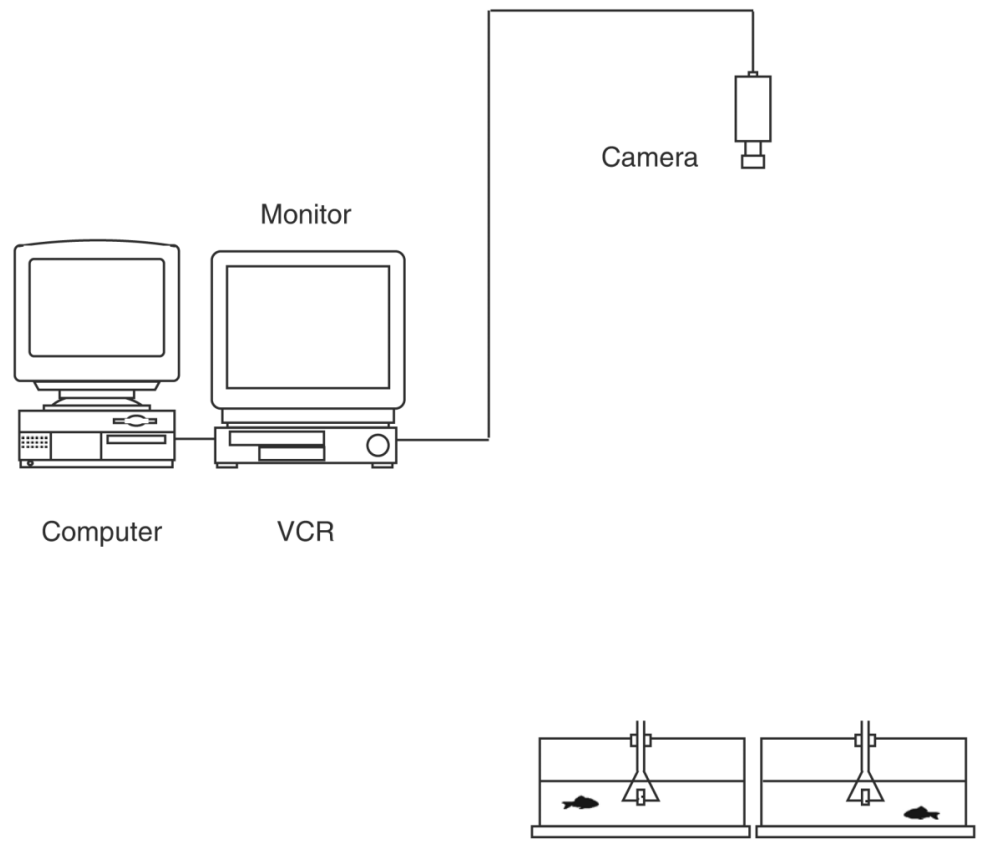

Experimental tanks

Fig. 1. The experimental set-up for tests of the swimming behaviour of crucian carp. Only two out of a total of four circular, experimental tanks are shown here. The behaviour of experimental fish is recorded by an centrally placed overhead video camera linked to a computer running motion analysis software.

$28, p=0.150$ ), nor did the coefficient of variation for turning rate (shallow-bodied fish: $1.82 \pm 0.32$, deep-bodied fish: $1.96 \pm 0.23$; Wilcoxon two-sample test: $\mathrm{Z}=1.277, \mathrm{n}$ $=28, p=0.202$ ). Velocities used by both morphs were significantly lower than predicted $U_{m c}$ values, the velocity associated with the minimum energy cost per unit distance (shallow-bodied fish: $\mathrm{U}_{\mathrm{mc}}=14.6 \mathrm{~cm} \mathrm{~s}^{-1}$, t-test: $\mathrm{t}_{15}=-22.6$, $\mathrm{p}<0.0001$; deep-bodied fish: $\mathrm{U}_{\mathrm{mc}}=10.5 \mathrm{~cm} \mathrm{~s}^{-1}$, $\mathrm{t}$-test: $\mathrm{t}_{11}=$ $-15.0, \mathrm{p}<0.0001)$. As both morphs were swimming at velocities below $U_{m c}$ (Fig. 4a), costs of transport were higher than predicted by models of energy minimisation per unit distance (Fig 4a, shallow-bodied fish, COT at average swimming velocity $\overline{\mathrm{U}}: 1.151$; deep-bodied fish, COT at $\bar{U}: 0.731)$. In terms of relative cost of transport, $\Delta$ COT, deep-bodied fish had an average COT that was $33.2 \%$ higher than at $\mathrm{U}_{\mathrm{mc}}$ (Fig. 4b), while shallow-bodied fish swam at an average COT that was $62.6 \%$ higher than at $\mathrm{U}_{\mathrm{mc}}$ (Fig. 4b).

\section{Discussion}

The results demonstrate that deep-bodied crucian carp show a lower variability in swimming velocity than shallow-bodied conspecifics. In contrast, the two morphs did not differ in mean swimming velocity, turning rate, or turning rate variability, three parameters that could influ- ence the result (Boisclair and Tang 1993, Ehlinger 1999, Neumeister et al. 2004). Hence, the experiment indicates an association between morphology and swimming variability. Such a pattern is predicted when deep-bodied individuals suffer a greater hydrodynamic drag and steeper power curves (Pettersson and Hedenström 2000), but could also be influenced by factors such as relative muscle mass distribution (Videler 1993, Webb and Gardiner Fairchild 2001), population differences (Pettersson 1999, Pettersson et al. 2000), and motivational differences (Irving and Magurran 1997).

In terms of muscle mass, fast-start performance is generally enhanced by having a large body depth and a large muscle mass relative to the total body mass (Weihs 1973, Videler 1993). Following this, deep-bodied individuals can be expected to be better at fast-starts than shallow-bodied conspecifics, a quality that could work towards a more variable use of swimming velocities. However, contrary to this, it was shallow-bodied, rather than deep-bodied, individuals that had the most variable velocities, indicating that fast-start performance played a less significant role during routine swimming. It should be noted that fish were length-matched in order to standardise available forward thrust and the expected routine swimming velocity (Pettersson and Hedenström 2000, Webb and Gardiner Fairchild 2001). By necessity, this meant that deep-bodied individuals had a greater body mass than shallow-bodied 

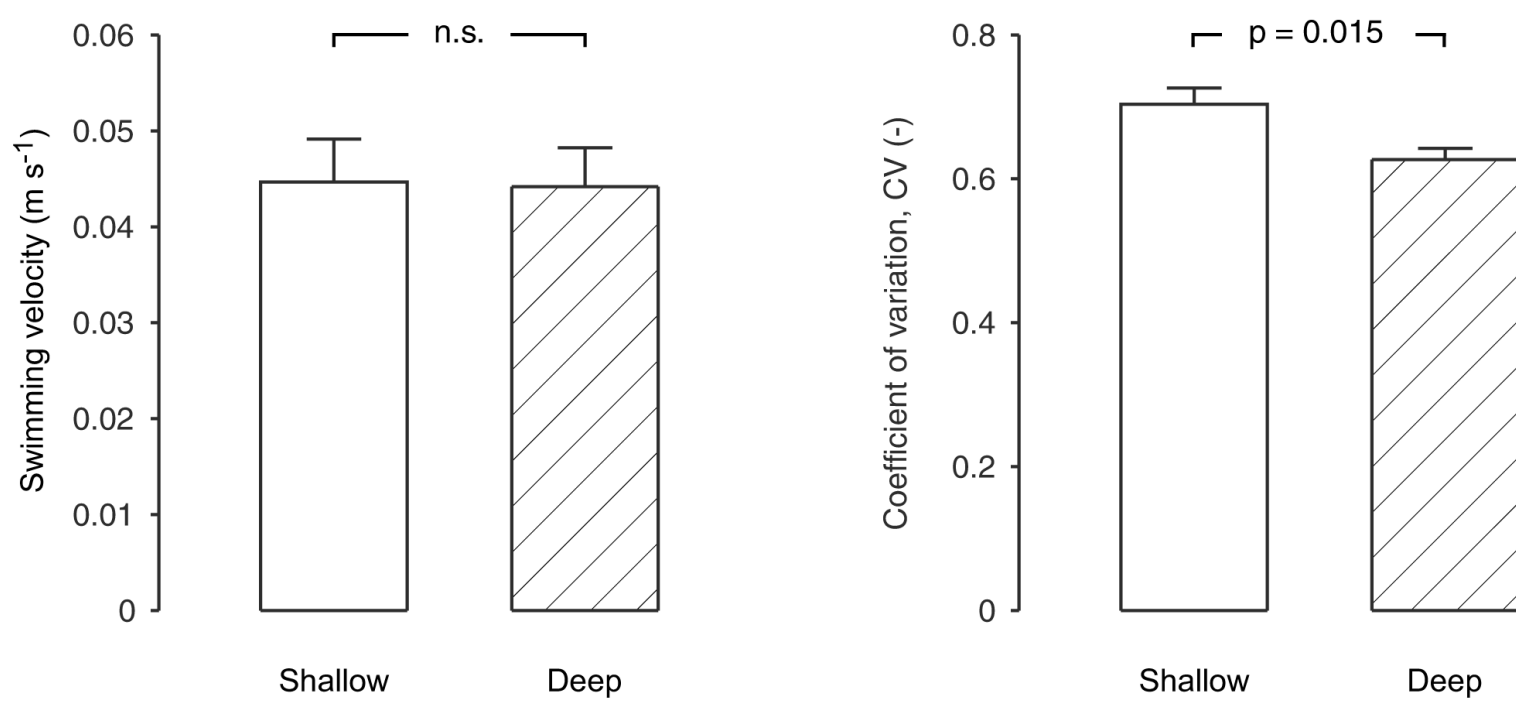

Fig. 2. Characteristics of swimming behaviour for shallow-bodied (shallow, $\mathrm{n}=16$ ) and deep-bodied (deep, $\mathrm{n}=12) \mathrm{crucian}$ carp. $(\mathrm{a})$ swimming velocity (+1 SE, measured per individual), (b) coefficient of variation for swimming velocity $(+1$ SE; measured per individual over the focal $5 \mathrm{~min}$ period). Significance levels are given above bars, n.s. denotes non-significant difference.

conspecifics, a compromise often used when investigating effects of phenotypic variation (Pettersson et al. 2000, Webb and Gardiner Fairchild 2001). The logical next step will be to generalise these results through a covariancebased comparison of swimming velocities and variability

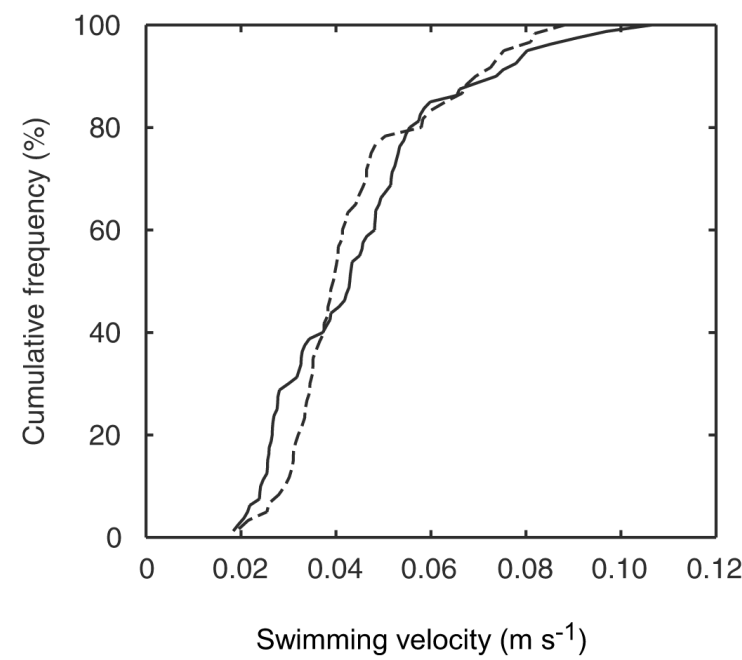

Fig. 3. Cumulative frequency distribution of all observed swimming velocities (averaged per minute) for the two crucian carp morphs (solid line denotes shallow-bodied individuals, and broken line denotes deep-bodied individuals). over a range of body lengths (i.e. compensating for allometric effects; Pettersson and Brönmark 1999).

Another important factor to take into consideration is whether the results could be affected by motivational differences between morphs. Such differences could either be due to insufficient acclimatisation or a result of genetic or developmentally fixed motivational differences between the two populations from which the experimental animals were collected.

In terms of acclimatisation, either morph could have reacted to the experimental set-up with generally more cautious or excited behaviour (cf. Irving and Magurran 1997). No such differences were observed, suggesting that the acclimatisation to indoor conditions and handling had been long enough. In particular, average velocity, one of the most commonly used measures of threat-sensitive behaviour in fish (Godin 1997, Pettersson et al. 2000) was similar in both morphs. The normal response to predation risk in crucian carp is marked reductions in activity followed by immobility (Pettersson and Brönmark 1993, Pettersson et al. 2000) but this was not observed in any of the trials (L. B. Pettersson, pers. obs.). Typically, carp swimming velocities reached levels that remained stable for the rest of the acclimation period within approximately 10 minutes after being added to the experimental pools.

Could then genetic or developmentally fixed motivational differences between deep-bodied and shallow-bodied individuals have affected the variability in swimming 
a)

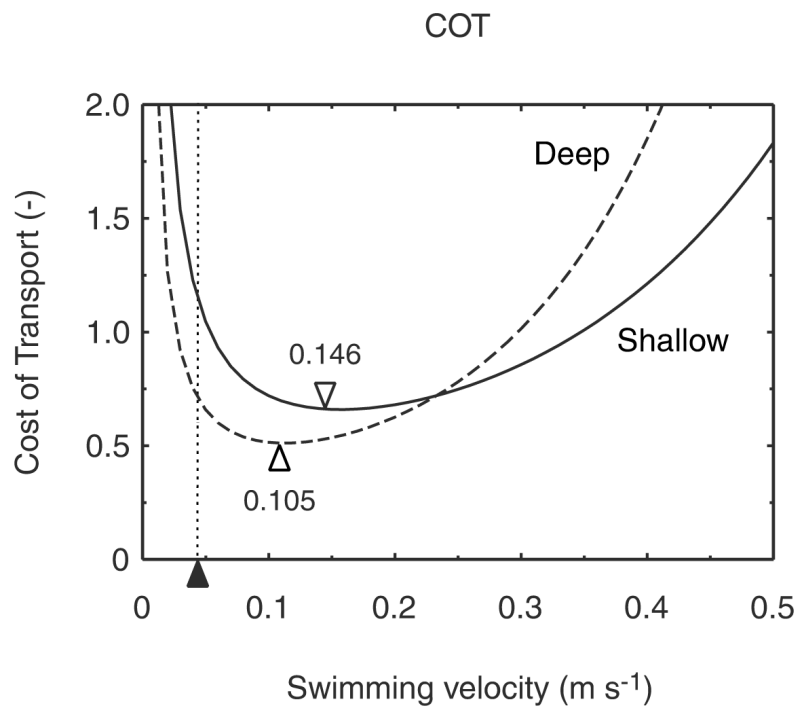

b)

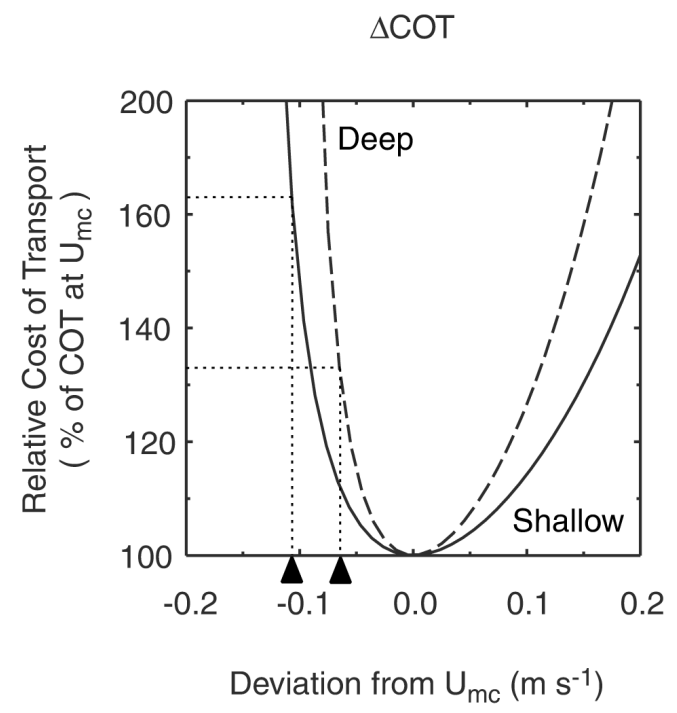

Fig. 4. Cost of transport (COT) and relative cost of transport ( $\triangle \mathrm{COT}$ ) for shallow-bodied and deep-bodied crucian carp. (a) cost of transport as a function of swimming velocity. The metabolic cost for the shallow-bodied morph is $\mathrm{P}(\mathrm{U})=0.0044 \times \mathrm{e}^{6.84 \times \mathrm{U}}$ (solid line, denoted shallow), and for the deep-bodied morph: $\mathrm{P}(\mathrm{U})=0.0035 \times \mathrm{e}^{9.56 \times \mathrm{U}}$ (broken line, denoted deep). Masses used in calculations are $11.9 \mathrm{~g}$ (shallow-bodied morph) and $17.0 \mathrm{~g}$ (deep-bodied morph). Dotted line denotes average swimming velocity $\overline{\mathrm{U}}$ for the two morphs. In (b), velocities have been standardised to $U_{m c}$ and the relative cost of transport $(\Delta C O T)$ for average individuals of the two morphs is shown as a function of the deviation from $\mathrm{U}_{\mathrm{mc}}$. Solid line (shallow) denotes the shallow-bodied morph and the broken line (deep) denotes the deep-bodied morph. Dotted lines denote deviations from $\mathrm{U}_{\mathrm{mc}}$ and associated relative costs of transport $(\Delta C O T)$ for the two morphs.

velocity? Consistent differences in e.g. predation pressure or food abundance can select for permanent or long-lasting differences in swimming behaviour (cf. Godin 1997, Ghalambor et al. 2003). Potentially, deep-bodied individuals coexisting with predators could be less prone to use variable velocities as a consequence of selection to reduce conspicuousness to predators. It could also be argued that swimming during foraging and exploratory behaviour might be less flexible in deep-bodied fish following high food abundance during ontogeny. Previous studies using the present population pair and others (Pettersson and Brönmark 1993, 1997, Brönmark and Pettersson 1994, Nilsson et al. 1995, Pettersson et al. 2000) have found that a number of behavioural parameters (e.g. foraging behaviour, swimming activity) are indistinguishable between morphs and repeatable between populations after 1-2 months of acclimation. Whether or not swimming variability differs from this pattern by being selectively affected by previous population differences despite substantial acclimation remains to be investigated. Ultimately, to generalise these findings it will be necessary to widen the approach from the single population pair comparison used here up to several scales, from within-population variability, to species level comparisons.

Unexpectedly, despite patterns of variability following model predictions, both morphs used velocities that were significantly lower than $\mathrm{U}_{\mathrm{mc}}$, the velocity associated with minimum energy cost per unit distance. Thus, experimental fish appeared not to be following a pure cost-of-transport (COT) minimisation strategy but were instead accepting significantly elevated costs $(\triangle C O T$ for deep-bodied individuals: 133\%; shallow-bodied individuals: 163\%). This raises important questions about how the Pettersson and Hedenström (2000) model can be applied. While minimising COT may be the most successful strategy during e.g. migration, a strict adherence to this criterion may be less important during activities such as exploratory behaviour, active feeding, or predator avoidance (Hedenström and Alerstam 1995, Pettersson et al. 2001, Webb and Gardiner Fairchild 2001). Such behaviour can be analysed as routine movement, i.e. situations where animals move about freely (Webb 1991, Boisclair and Tang 1993, Tang et al. 2000, Neumeister et al. 2004). Routine movement can then either be analysed along trajectories (Boisclair and Tang 1993, Tang et al. 2000, Neumeister et al. 2004) or modelled as patch choice or sequential path models (Hedenström and Alerstam 1995, Pettersson and Hedenström 2000). Generally, routine movement is more costly than forced movement at uniform velocities. In fish, it has been estimated to be from about 3 to 30 times as costly (Boisclair and Tang 1993, Tang et al. 2000) and is likely to increase the COT and correspondingly decrease 
the routine swimming $\mathrm{U}_{\mathrm{mc}}$. Furthermore, data from field experiments and other laboratory studies (Nilsson et al. 1993, Greenberg et al. 1995, Pettersson et al. 2000, Pettersson et al. 2001), indicate that crucian carp normally swim at just half of the velocity normally considered to be baseline routine activity, about one body length covered per second (Beamish 1978, Wootton 1990). Hence, crucian carp appear to be comparatively slow swimmers in general and this characteristic could further add to an overestimation of their optimal swimming velocity. However, as long as power curve shape remains qualitatively and consistently different between morphs, predictions derived from power curve shape remain valid and $\triangle \mathrm{COT}$ analysis still suggests that deep-bodied individuals should show a lower variability in swimming velocity than more fusiform conspecifics (Pettersson and Hedenström 2000). Standard models of swimming behaviour do not cover such an association between morphology and swimming variability. In other words, power curve shape underlying the $\triangle \mathrm{COT}$ relation, either including or excluding effects of unsteadiness during routine movement (Webb 1991, Boisclair and Tang 1993, Tang et al. 2000), can be seen as describing baseline requirements that context-dependent strategies will have to accommodate (Hedenström and Alerstam 1995). The actual influence of different optimisation criteria on $\triangle$ COT-based strategies remains to be investigated.

The results found in the present study support arguments by Pettersson and Hedenström (2000) that differences in morphology may interact with behavioural change, either through phenotypic plasticity (McLaughlin et al. 1999, Pakkasmaa and Piironen 2000, Adams et al. 2003), or as evolutionary responses (Adams et al. 2003, West-Eberhard 2003, Ohlberger et al. 2006). In particular, associations between swimming variability and morphology would be expected to manifest in polymorphic populations. For instance, many examples of freshwater fish polymorphisms could well be associated with differences in power curve shape and corresponding differences in swimming variability (Ehlinger 1999, Schluter 2000, Robinson and Parsons 2002, Adams et al. 2003, Snorrason and Skúlason 2004). Typically, fusiform individuals of a range of species are found specialising on zooplankton while deep-bodied conspecifics specialise on benthic, more sedentary prey (Ehlinger 1999, Schluter 2000, Robinson and Parsons 2002, Svanbäck and Eklöv 2004). Following hydrodynamic theory, fusiform individuals should then have relatively shallow power curves while deep-bodied ones should have steeper power curves (Webb 1975, Pettersson and Brönmark 1999). As power curve shape can be expected to influence the energetic cost of deviating from optimal swimming velocities, it is likely that these morphs experience small but consistent differences in the relative payoff of using variable vs invariant velocities (Pettersson and Hedenström 2000). This would then work towards variable swimming velocities in fusiform individuals and relatively invariant velocities in deep-bodied individuals. Little data is yet available to address these patterns among species, but the current rapid development in motion analysis software (e.g. Neumeister et al. 2004) is likely to change this in the near future.

The approach used in the present paper offers a testable framework for understanding associations between swimming variability and morphology in dimorphic species and also links these pressures to a potential feedback between morphology, ecological energetics, and behavioural flexibility. A feedback in which individuals at one extreme can afford using variable swimming velocities at little cost while individuals at the other extreme experience an energetic advantage if they restrict their use of swimming velocities is likely to add significantly to other selective forces favouring divergence into e.g. trophic polymorphisms (Ehlinger 1999, Schluter 2000, Robinson and Parsons 2002), habitat segregation (McLaughlin et al. 1999, Snorrason and Skúlason 2004) or differing antipredator tactics (Krause et al. 1998, Pettersson et al. 2000, Ghalambor et al. 2003). Given the importance of understanding how biological diversity is generated and maintained, doing so through functional analysis of phenotypic variation in dimorphic species promises to be a valuable tool for future research.

Acknowledgements - I thank one anonymous reviewer for valuable comments on this manuscript. Financial support was received from The Swedish Foundation for International Cooperation in Research and Higher Education, Hellmuth Hertz' Foundation, and the Nordic Academy for Advanced Study. This study was approved by the Malmö/Lund Committee for Animal Experiment Ethics (permission no. M111-96 and M222-97).

\section{References}

Adams, C. E. et al. 2003. Epigenetic regulation of trophic morphology through feeding behaviour in Arctic charr, Salvelinus alpinus. - Biol. J. Linn. Soc. 78: 43-49.

Beamish, F. W. H. 1978. Swimming capacity. - In: Hoar, W. S. and Randall, D. J. (eds), Fish physiology, Vol. VII, Locomotion. Academic Press, pp. 101-187.

Blake, R. W. 1983. Fish locomotion. - Cambridge Univ. Press.

Boisclair, D. and Tang, M. 1993. Empirical analysis of the influence of swimming pattern on the net energetic cost of swimming in fishes. - J. Fish Biol. 42: 169-183.

Brönmark, C. and Pettersson, L. B. 1994. Chemical cues from piscivores induce a change in morphology in crucian carp. Oikos 70: 396-402.

Brönmark, C. et al. 1999. Predator-induced defense in crucian carp. - In: Tollrian, R. and Harvell, C. D. (eds), The ecology and evolution of inducible defenses. Princeton Univ. Press, pp. 203-217.

Castro-Santos, T. 2005. Optimal swim speeds for traversing velocity barriers: an analysis of volitional high-speed swimming behavior of migratory fishes. - J. Exp. Biol. 208: 421-432.

Ehlinger, T. J. 1999. Ecology, phenotype, and character evolution in bluegill sunfish. - In: Foster, S. A. and Endler, J. A. (eds), 
Geographic variation in behavior: perspectives on evolutionary mechanisms. Oxford Univ. Press, pp. 121-138.

Eklöv, P. and Persson, L. 1995. Species-specific antipredator capacities and prey refuges - Interactions between piscivorous perch (Perca fuviatilis) and juvenile perch and roach (Rutilus rutilus). - Behav. Ecol. Sociobiol. 37: 169-178.

Endler, J. A. 1995. Multiple-trait coevolution and environmental gradients in guppies. - Trends Ecol. Evol. 10: 22-29.

Ghalambor, C. K. et al. 2003. Multi-trait selection, adaptation, and constraints on the evolution of burst swimming performance. - Integr. Comp. Biol. 43: 431-438.

Godin, J.-G. J. 1997. Evading predators. - In: Godin, J.-G. J. (ed.), Behavioural ecology of teleost fishes. Oxford Univ. Press, pp. 191-236.

Greenberg, L. A. et al. 1995. Effects of prey species composition and habitat structure on foraging by two functionally distinct piscivores. - Oikos 74: 522-532.

Grossman, G. D. et al. 2002. A new optimal foraging model predicts habitat use by drift-feeding stream minnows. - Ecol. Freshwater Fish 11: 2-10.

Hedenström, A. and Alerstam, T. 1995. Optimal flight speed of birds. - Phil. Trans. R. Soc. B. 348: 471-487.

Hölker, F. 2003. The metabolic rate of roach in relation to body size and temperature. - J. Fish Biol. 62: 565-579.

Irving, P. W. and Magurran, A. E. 1997. Context-dependent fright reactions in captive European minnows: the importance of naturalness in laboratory experiments. - Anim. Behav. 53: 1193-1201.

Kaufmann, R. and Wieser, W. 1992. Influence of temperature and ambient oxygen on the swimming energetics of cyprinid larvae and juveniles. - Environ. Biol. Fish. 33: 8795.

Krause, J. et al. 1998. Refuge use by fish as a function of body length-related metabolic expenditure and predation risks. Proc. R. Soc. B 265: 2373-2379.

Magellan, K. et al. 2005. Quantifying male attractiveness and mating behaviour through phenotypic size manipulation in the Trinidadian guppy, Poecilia reticulata. - Behav. Ecol. Sociobiol. 58: 366-374.

McLaughlin, R. L. et al. 1999. Adaptive peaks and alternative foraging tactics in brook charr: evidence of short-term divergent selection for sitting-and-waiting and actively searching. - Behav. Ecol. Sociobiol. 45: 386-395.

Neumeister, H. et al. 2004. Dynamical analysis reveals individuality of locomotion in goldfish. - J. Exp. Biol. 207: 697-708.

Nilsson, G. E. et al. 1993. Anoxic depression of spontaneous locomotor activity in crucian carp quantified by a computerized imaging technique. - J. Exp. Biol. 180: 153-162.

Nilsson, P. A. et al. 1995. Benefits of a predator-induced morphology in crucian carp. - Oecologia 104: 291-296.

Noldus Inc. 1997. Ethovision: video tracking, motion analysis and behavior recognition system. Reference manual ver. 1.90. - Noldus Information Technology b.v.

Odell, J. P. et al. 2003. Morphological and enzymatic correlates of aerobic and burst performance in different populations of Trinidadian guppies Poecilia reticulata. - J. Exp. Biol. 206: 3707-3718.

Ohlberger, J. et al. 2006. Swimming efficiency and the influence of morphology on swimming costs in fishes. - J. Comp. Physiol. B-Biochem. Syst. Environ. Physiol. 176: 17-25.
Pakkasmaa, S. and Piironen, J. 2000. Water velocity shapes juvenile salmonids. - Evol. Ecol. 14: 721-730.

Pettersson, L. B. 1999. Phenotypic plasticity and the evolution of an inducible morphological defence in crucian carp. $-\mathrm{PhD}$ thesis, Lund University, Sweden.

Pettersson, L. B. and Brönmark, C. 1993. Trading off safety against food: state dependent habitat choice and foraging in crucian carp. - Oecologia 95: 353-357.

Pettersson, L. B. and Brönmark, C. 1997. Density-dependent costs of an inducible morphological defense in crucian carp. - Ecology 78: 1805-1815.

Pettersson, L. B. and Brönmark, C. 1999. Energetic consequences of an inducible morphological defence in crucian carp. Oecologia 121: 12-18.

Pettersson, L. B. and Hedenström, A. 2000. Energetics, cost reduction and functional consequences of fish dimorphism. Proc. R. Soc. B 267: 759-764.

Pettersson, L. B. et al. 2000. Predator recognition and defence strategies in crucian carp. - Oikos 88: 200-212.

Pettersson, L. B. et al. 2001. The diel activity of crucian carp, Carassius carassius, in relation to chemical cues from predators. - Environ. Biol. Fish. 61: 341-345.

Robinson, B. W. and Parsons, K. J. 2002. Changing times, spaces, and faces: tests and implications of adaptive morphological plasticity in the fishes of northern postglacial lakes. - Can. J. Fish. Aquat. Sci. 59: 1819-1833.

SAS Institute 1999. SAS ver. 8.2. - SAS Institute Inc.

Schluter, D. 2000. The ecology of adaptive radiation. - Oxford Univ. Press.

Siegel, S. and Castellan, J. N. 1988. Nonparametric statistics for behavioral sciences. - McGraw-Hill.

Snorrason, S. S. and Skúlason, S. 2004. Adaptive speciation in northern freshwater fishes. - In: Dieckmann, U. et al. (eds), Adaptive speciation. Cambridge Univ. Press, pp. 210-228.

Svanbäck, R. and Eklöv, P. 2004. Morphology in perch affects habitat specific feeding efficiency. - Funct. Ecol. 18: 503510 .

Tang, M. et al. 2000. Influence of body weight, swimming characteristics, and water temperature on the cost of swimming in brook trout (Salvelinus fontinalis). - Can. J. Fish. Aquat. Sci. 57: 1482-1488.

Tucker, V. A. 1975. The energetic cost of moving about. - Am. Sci. 63: 413-419.

Videler, J. J. 1993. Fish swimming. - Chapman and Hall.

Webb, P. W. 1975. Hydrodynamics and energetics of fish propulsion. - Bull. Fish. Res. Bd. Can. 190: 1-159.

Webb, P. W. 1991. Composition and mechanics of routine swimming of rainbow trout, Oncorhynchus mykiss. - Can. J. Fish. Aquat. Sci. 48: 583-590.

Webb, P. W. and Gardiner Fairchild, A. 2001. Performance and maneuverability of three species of teleostean fishes. - Can. J. Zool. 79: 1866-1877.

Weihs, D. 1973. The mechanism of rapid starting in slender fish. - Biorh. 10: 343-350.

West-Eberhard, M. J. 2003. Developmental plasticity and evolution. - Oxford Univ. Press.

Wootton, R. J. 1990. Ecology of teleost fishes. - Chapman and Hall.

Zar, J. H. 1999. Biostatistical analysis, 4th ed. London, pp. 527530. 